\title{
The Daily Review of central venous access as prevention and control of complications: the photographic archive to check in hospital and at home.
}

\author{
Mastrandrea G, Bradascio G, Bizzoca A, Albergo V, Nardozza D, Boccuzzi R, Marrone M, \\ Cileo A, Garofalo D, Carravetta G, Department of Anestesiology and Intensive Care Unit - \\ Institute for Cancer Treatment and Research Giovanni Paolo II - BARI, ITALY
}

The aim of our work is to identify the diagnostic therapeutic assistance path (in Italian: PDTA - Percorso Diagnostico Terapeutico Assistenziale, the protocol adopted in Puglia Region in the south of (taly) in order to detect early the catheter related complications, to guarantee effective therapeutic strategies and to involve patients in safety initiatives as medication checks. We used this protocol in the Puglia Oncological Network (in Italian: ROP - Rete Oncologica Pugliese)

\section{in hospital...}

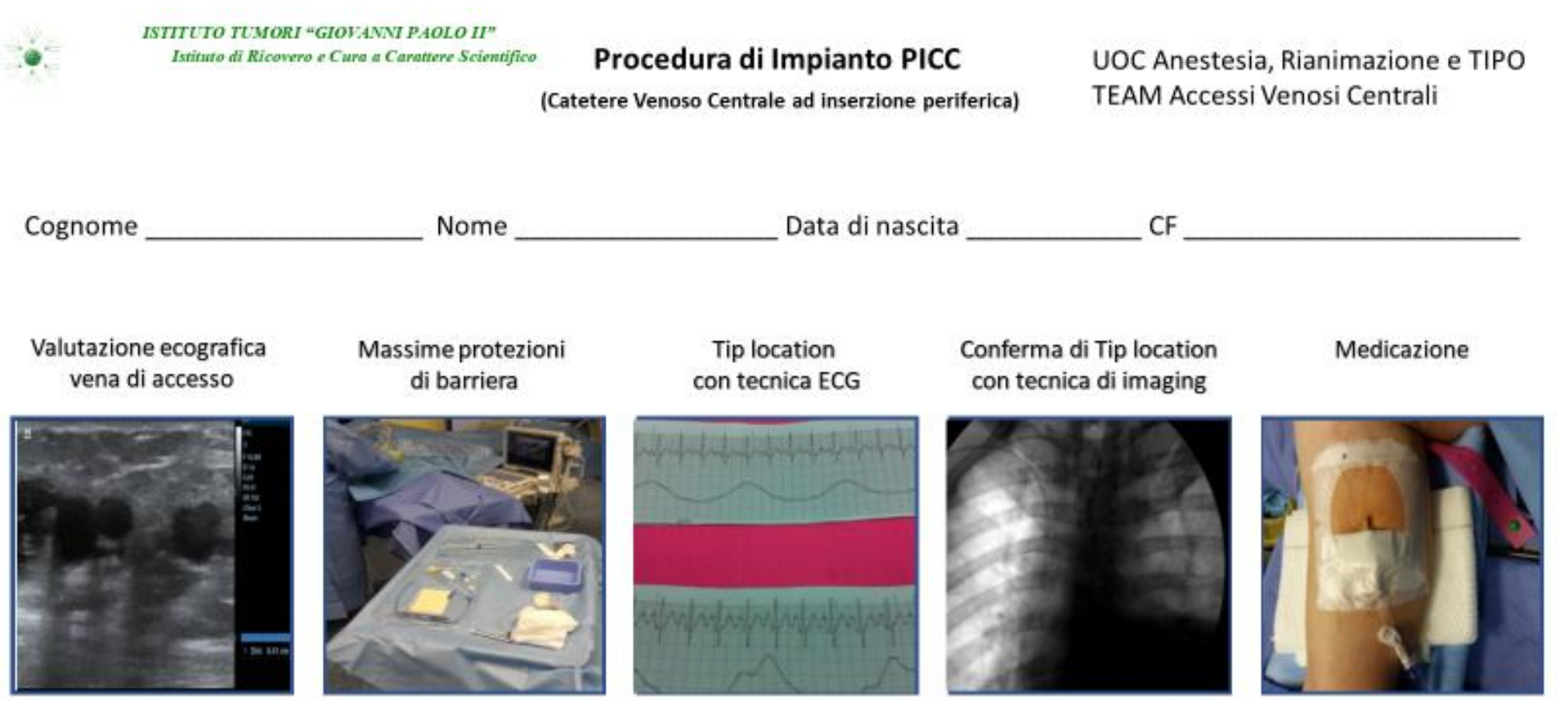

BARI, Firma dell'Impiantatore

During the first dressing the patient is informed about the complications of central venous catheter and the good practices for the dressing's management. Moreover, the patient receives a checklist of the catheter related injury and the devices recommended by international guideline. Then the patient is invited to photograph any change of dressing and to send these pictures to a dedicated email address. The dressing's management clinic evaluates the pictures and publish the most significant photos on the site of the Cancer Institute.

\section{at home...}
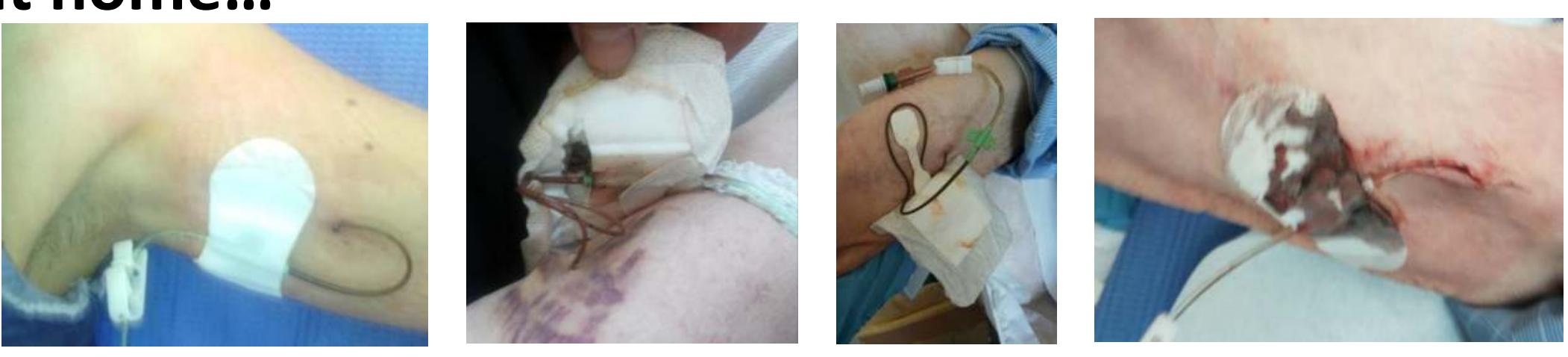

The daily review of central venous access assessed by a photographic archive improved by the dressing's management clinic in hospital and by the patients at home. This photographic documentation can be updated (daily, if necessary) by the patient or the caregiver in case of suspected catheter related complications.

Cotidie morimur; cotidie enim demitur aliqua pars vitae, et tunc quoque cum crescimus vita decrescit. Infantiam amisimus, deinde pueritiam, deinde adulescentiam. Usque ad hesternum quidquid transit temporis perit; hunc ipsum quem agimus diem cum morte dividimus. Quemadmodum clepsydram non extremum stilicidium exhaurit sed quidquid ante defluxit, sic ultima hora qua esse desinimus non sola mortem facit sed sola consummat; tunc ad illam pervenimus, sed diu venimus.

Seneca, Ad Lucilium

\section{Dressing's checklist}

$\checkmark$ NO secretions/pus/blood

$\checkmark$ NO spilling

$\checkmark$ NO erythema

$\checkmark$ NO edema

$\checkmark$ NO pain

$\checkmark$ Needlefree Connectors

$\checkmark$ Port Protector

$\checkmark$ Sutureless Device

$\checkmark$ Transparent semi-permeable dressing

$\checkmark$ Continuous release device of Chlorhexidine

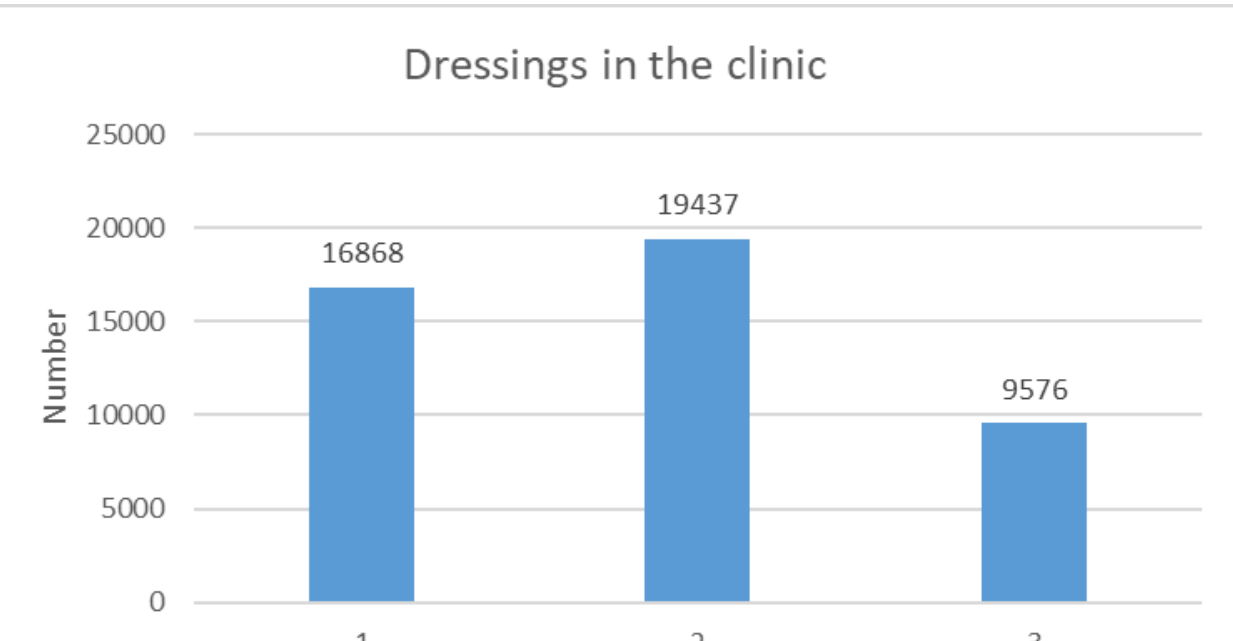

Year (from 2016 to 2018)

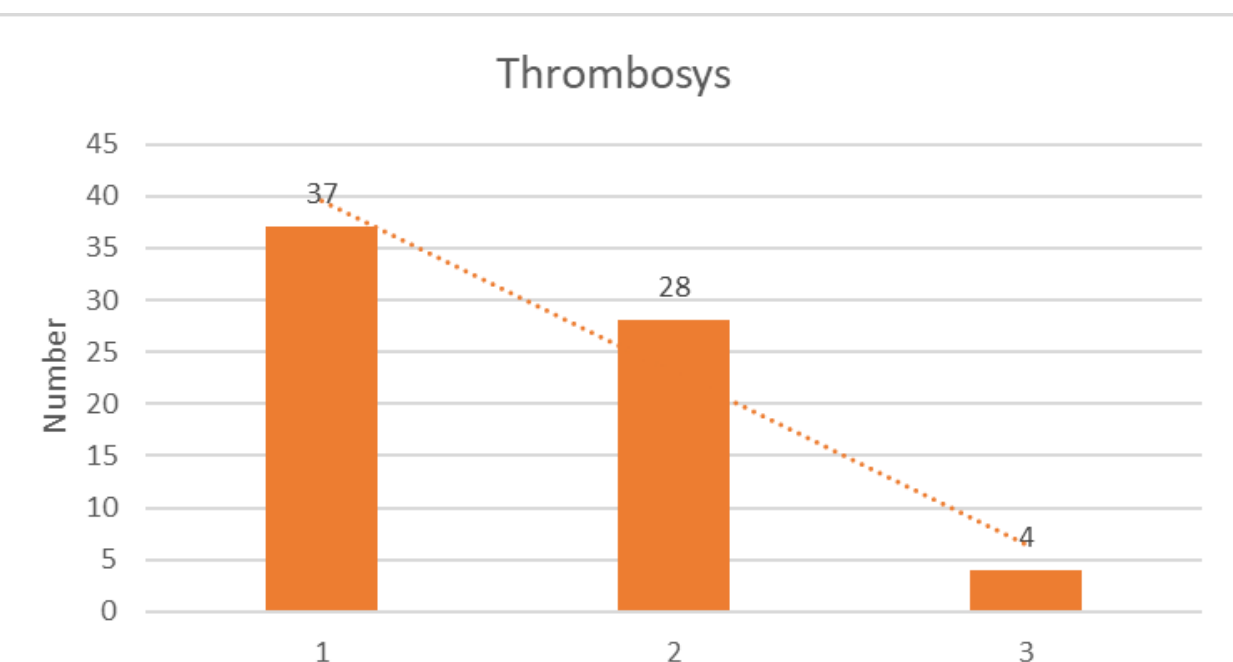

Year (from 2016 to 2018)

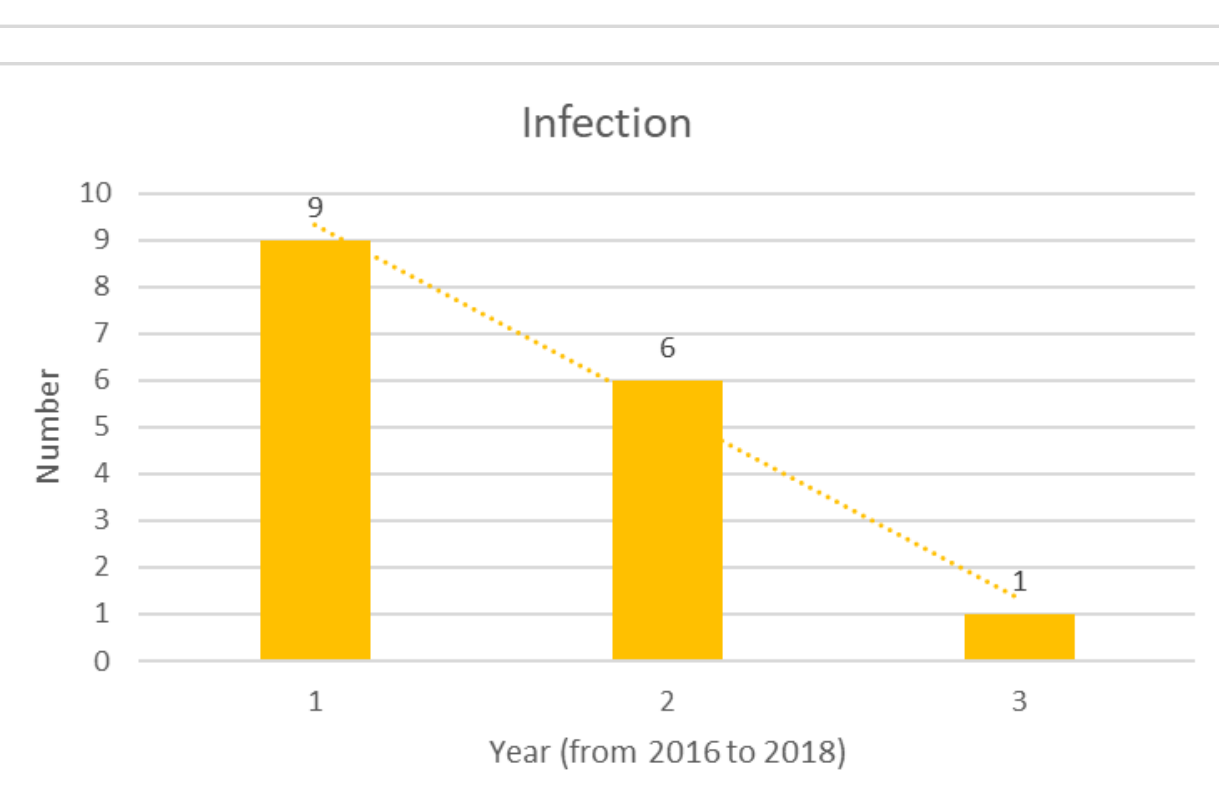

All patients involved in dressing checks All complication in home dressing
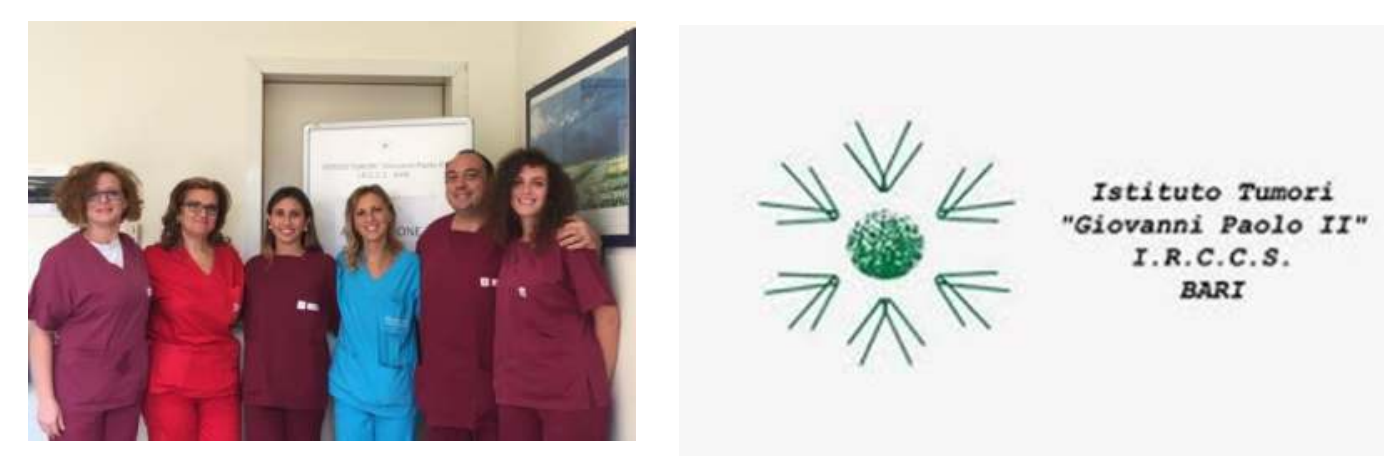